\title{
The evolution of robotics in China: accumulated experience and prospects
}

\author{
Marina S. Reshetnikova*, Irina A. Pugacheva, and Yulia D. Lukina \\ RUDN University, Miklukho-Maklaya St, 6, 117198 Moscow, Russian Federation
}

\begin{abstract}
In the context of globalization and the fourth industrial revolution (Industry 4.0), the development of robotics and AI has become one of the most important factors of economic and technological growth. A leadership race has already unfolded between the developed countries. Today, China is the undisputed leader in this industry and the largest consumer of industrial robots, but this was not always the case. To achieve leadership in this sphere, the Chinese government supports robotics startups in automotive, electronics, and logistics. The support is provided in the form of tax incentives and subsidies for $R \& D$. The purpose of the research was to forecast the industrial robots' market in China and answer whether it will keep its position in the future. The carried study showed that the market of industrial robots in China is increasing, significantly outpacing the dynamics of global indicators. The decline in the growth of the Chinese robotics market indicators can be explained by the consequences of the COVID-19 pandemic and trade tensions between the market leaders: China and the United States.
\end{abstract}

\section{Introduction}

In the context of globalization and the fourth industrial revolution (Industry 4.0), the development of robotics has become one of the most important factors of economic and technological growth [1]. As a result, a leadership race has already unfolded between the world's leading countries. Today, China is the undisputed leader in this industry and the largest consumer of industrial robots, but this was not always the case [2].

Until 2000, the use of industrial robots in China was negligible. In the 1970s, the country began research in industrial robots, samples, and the development of fundamental technologies. In 1990-2000 the development of prototypes of the initial models and their small-scale production began. In the late $1990 \mathrm{~s}$, the commercialization of domestic robot production began: industrial and research bases were created, and the first large national manufacturers appeared [3].

In 2001-2010, it was a stage for mass industrialization when Chinese companies began mass production of domestic industrial robots for general consumption. From 2011 to the present, a period of ultra-rapid development of the Chinese robotics industry has already started. As a result, in 2013, China has overtaken Japan to become the world's largest market for industrial robots.

\footnotetext{
*Corresponding author: reshetnikova-ms@rudn.ru
} 
The accelerated growth of the robotics industry in China is associated with reducing labor costs and increasing labor productivity, ensuring product quality control. In addition, demographic factors played an important role: a shortage of skilled labor, an increase in its price, and an aging population. The Chinese leadership believes that the development of robotics is significant for national security and recovery of entire economic sectors after the COVID-19 pandemic [4].

To achieve its goals, the Chinese government supports robotics startups in automotive, electronics, IT, and logistics. The support is provided in the form of tax incentives and subsidies for R\&D. The purpose of the research was to forecast the industrial robots' market in China and answer whether it will keep its position in the future.

\section{Materials and methods}

The authors used the theoretical and methodological foundations of scientific research as the general methodology. Empirical methods, methods of calculating indices, comparative analysis methods, and generalizations of statistical data were used to solve the problems. Together, these methods and scientific principles made it possible to ensure the study's reliability and the correctness of the conclusions.

The forecast of the industrial robots' market in China is performed using the linear regression method and an econometric model. The multiple linear regression equation will have the form:

$$
Y^{\wedge}=b_{0} * x_{0}+b_{1} * x_{1}+b_{2} * x_{2}+b_{n} * x_{n},
$$

where: b0, b1, b2, bn - parameters of the equation calculated by the method of least squares (LS).

The resulting variable is the estimated value of the volume of the industrial robot market in the current year (Fig. 6).

The following variable names were entered for the model:

- VOLUME$^{\wedge}$ - the volume of the industrial robot market, billion USD (calculated values).

- VOLUME - the volume of the industrial robot market, billion USD.

- PROD - the volume of production of industrial robots, thousands of units.

- SALES - the volume of sales of industrial robots, billion USD.

- INVEST - the volume of investments, billion USD.

- DENSITY - the density of robotics, the number of robots per 10 thousand employed in the industry.

The estimated equation:

$$
\text { VOLUME }^{\wedge}=57.88+0.09 * \text { PROD }-12.64 * \text { SALES }+0.94 * \text { INVEST }+0.26 * \text { DENSITY }
$$

To identify the overall growth trend of the China robotics market and calculate the forecast values until 2025, an econometric model of the Lin-Lin type was constructed, which depends on several factors: the volume of production of industrial robots, the volume of sales of industrial robots, the volume of investments and the density of robotics, the number of robots per 10 thousand employed in the industry.

\section{Results}

Now Asia is the largest robotics market, which can be divided into three sectors: industrial robots, service robots, and specialized robots. In this article, the authors analyzed the 
dynamics of indicators for industrial and service robots in the Chinese market. The immense market demand for robots in China is industrial robots $-71 \%$ as of 2018 . On the other hand, service robots show promising potential in the Chinese market (21\% in 2018), as many families use home robots. Furthermore, the rapid development of the healthcare sector creates prerequisites for the growth of this category in the future. (Fig. 1).

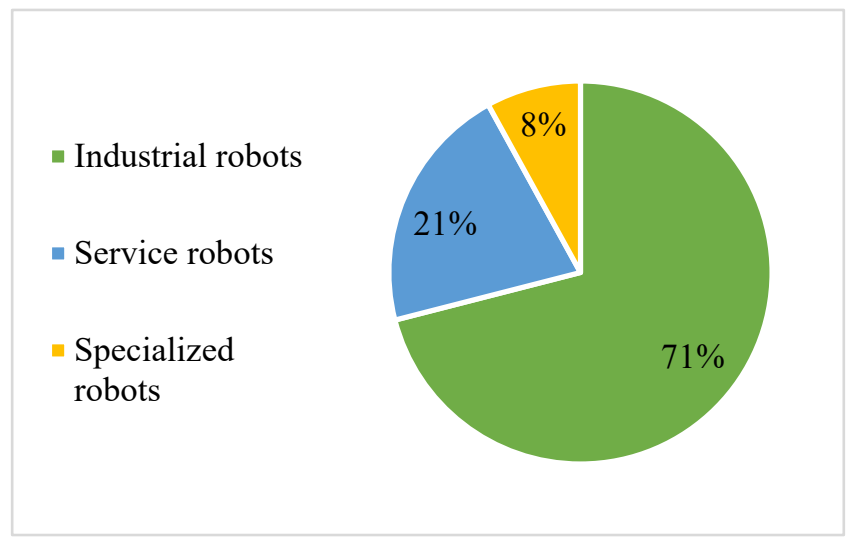

Source: Compiled by the authors, data collected from IFR reports: IFR (2019) [5], IFR (2020) [6].

Fig. 1. Types of robots. Market share in 2018.

The Chinese industrial robot market has maintained a positive trend throughout its development, occupying about a third of the global market. It is the world's largest market for industrial robot applications. According to IFR statistics, the density of industrial robots in China reached 187 units per 10 thousand employees in 2019, which is higher than the global average. It is expected that in 2021 this figure will reach a value of 232 robots, and by the end of 2025, this figure will increase by another 121 units (Figure 2).

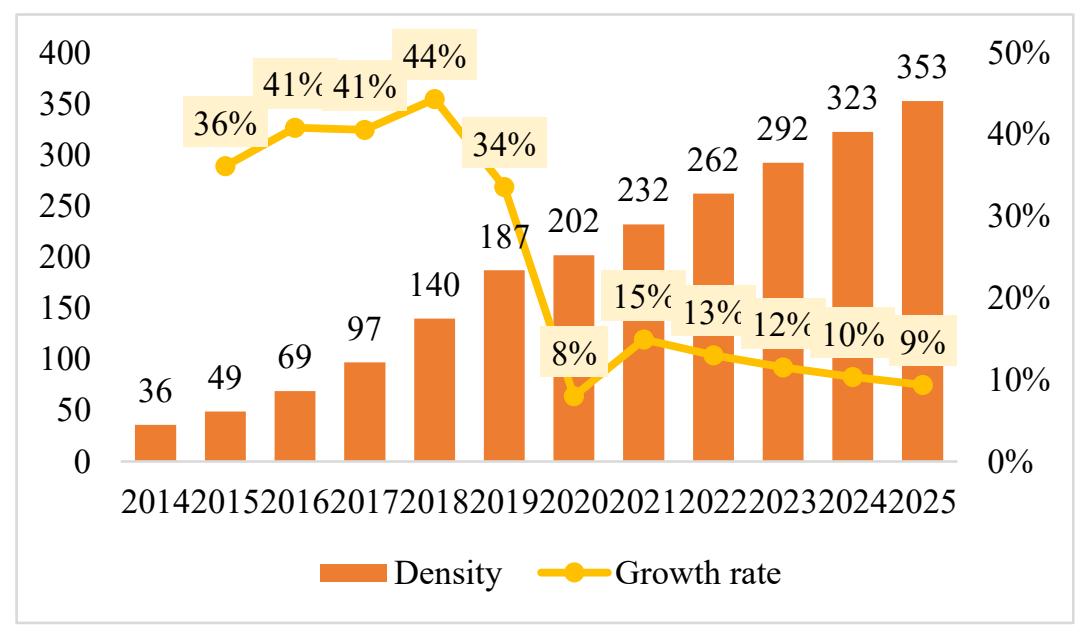

Source: Compiled by the authors, data collected from IFR reports: IFR (2019) [5], IFR (2020) [6].

Fig. 2. Dynamics of the density of robots per 10 thousand employees.

The Chinese robotics market is constantly growing. In 2019, the industrial robot market reached a value of $\$ 72.6$ billion $(+14.9 \%$ by 2018$)$, while the service robot market reached 
a value of $\$ 7.5$ billion $(+19.0 \%$ by 2018$)$. However, it is worth noting that the growth rate of these types of robots is different: the growth of industrial robots fell sharply in 2015, but since 2017 began to increase rapidly, the growth of service robots since 2017 , on the contrary, began to decrease (Figure 3). This is due to the continuous development of traditional industrial robots, simplifying their programming for complex tasks and the latest security systems [7].

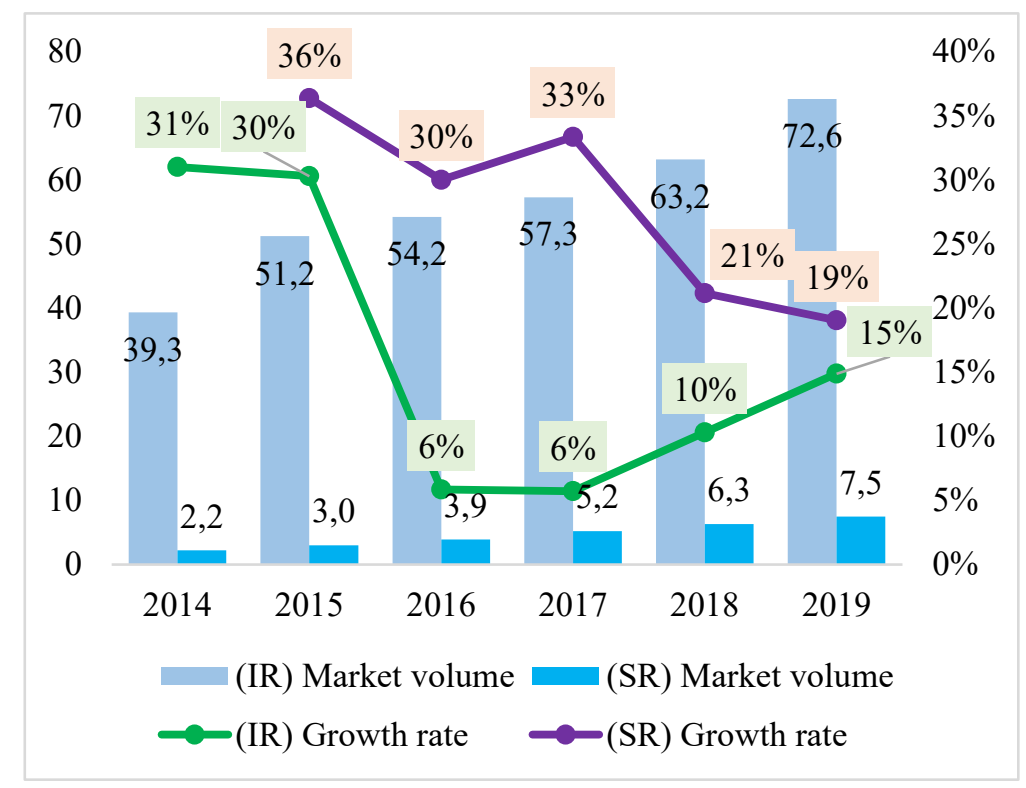

Source: Compiled by the authors, data collected from IFR reports: IFR (2019) [5], IFR (2020) [6].

Fig. 3. Dynamics of the market volume of industrial and service robots, billion dollars.

The service robots' market in China is rapidly expanding, becoming a bright application area of the robotics market. Due to the accelerating trend of population aging and the continued high demand for healthcare and education, China's service robots have huge market potential and development opportunities. As a result, autonomous mobile robots and automated vehicles used in logistics applications are expected to grow significantly, with sales exceeding $\$ 3$ billion by 2022 [8].

Figure 4 shows the dynamics of manufactured industrial robots in China and their sales in physical terms from 2012 to 2019, with a forecast until 2025. At the end of 2019, 120 thousand robots were produced, and 128 thousand units were sold, which is $18,2 \%$ and $22,1 \%$ less than in 2018, respectively [9]. It can be noted that in 2019, the indicators decreased significantly, but in 2020 they began to grow again. Thus, positive dynamics are expected until the end of the forecast period. By the end of 2025, the volume of industrial robots produced in China may reach a value of 280.6 thousand. As a result, units and the number of sales will increase to 194,6 thousand units. In addition, starting in 2020, the gap between manufactured and sold robots may change: production will grow at a higher rate than sales. 


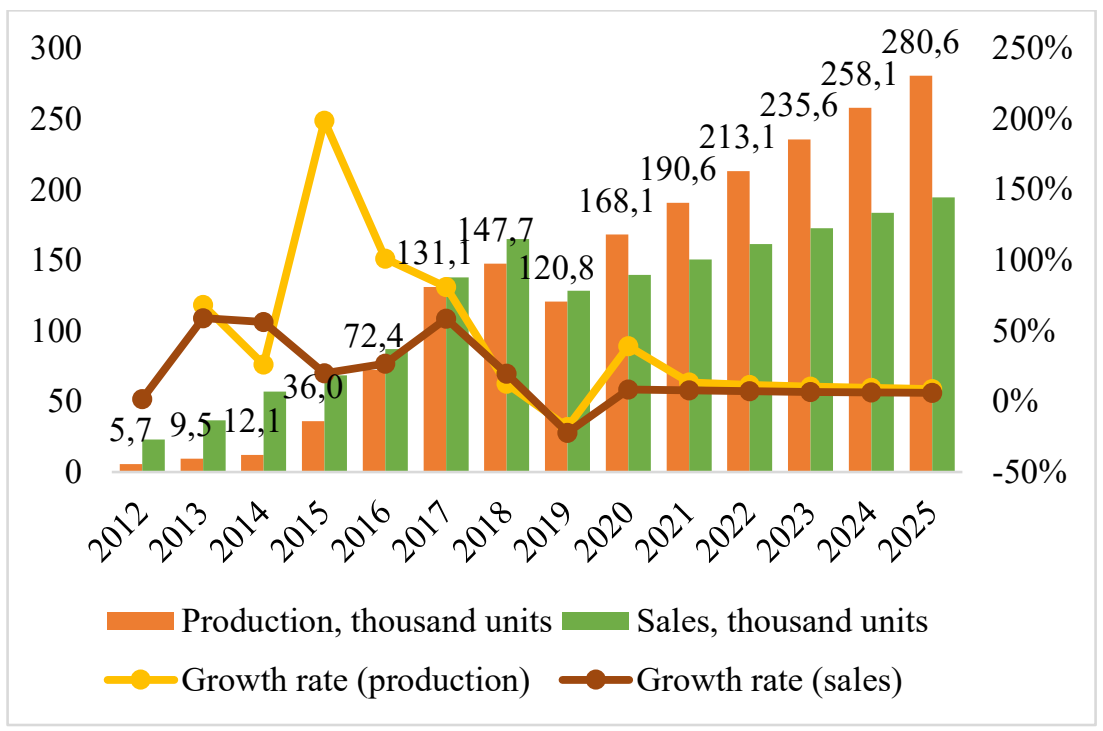

Source: Compiled by the authors, data collected from IFR reports: IFR (2019) [5], IFR (2020) [6].

Fig. 4. Dynamics of production and sales of industrial robots, thousand units.

China buys and manufactures more industrial robots than any other country, but its market is still dominated by Japanese companies, followed by manufacturers from Europe and South Korea [10].

In $2019, \$ 54,2$ billion was invested in robotics, which is $41 \%$ more than in the previous year. Investment is expected to reach $\$ 105,8$ billion in 2025 , but the drop in investment growth should be noted (Figure 5).

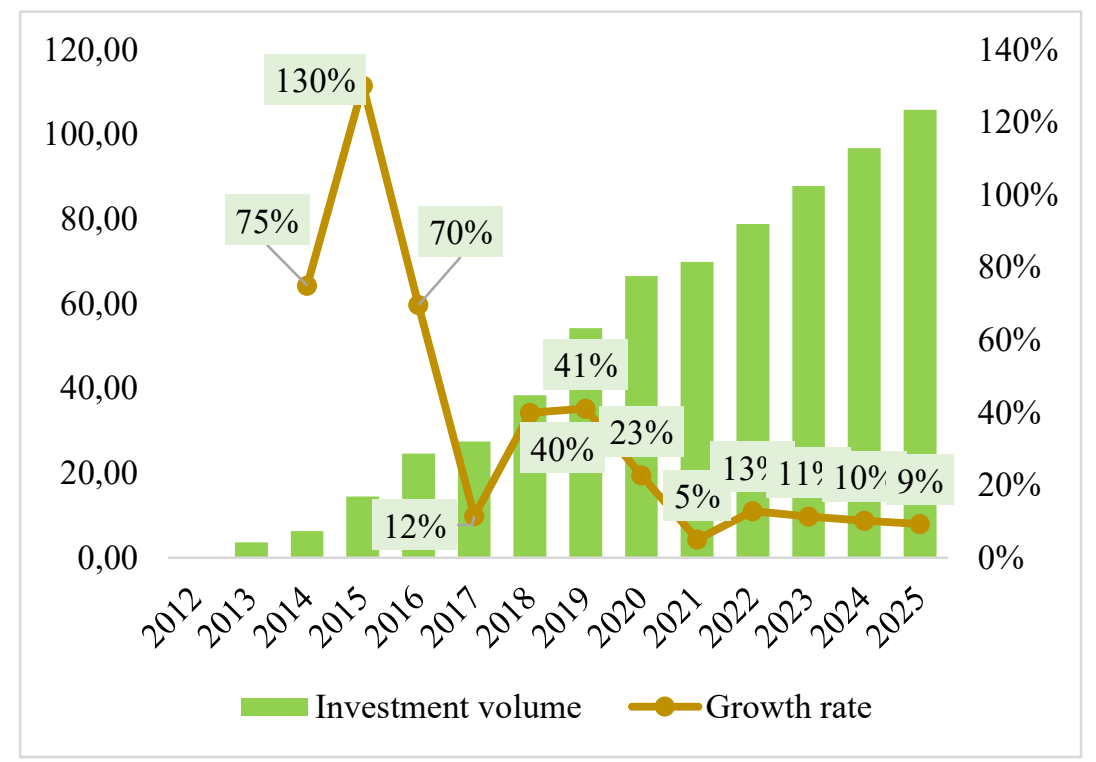

Source: Compiled by the authors, data collected from IFR reports: IFR (2019) [5], IFR (2020) [6].

Fig. 5. Dynamics of investment volume, billion dollars (2012-2025). 
Often, investments in China are flown not in applied but basic research. Basic research focuses on developing manipulators and controllers, while applied research focuses on the component base and specific functions required by the end-user and industry. Because of this, the industrial R\&D base lacks vital breakthrough technologies, which makes it less competitive [11].

According to the forecast of IDC Corporation, the robotics market in China will multiply and reach $\$ 80.5$ billion by 2022 , accounting for almost $40 \%$ of the global total [12]. The Chinese government actively supports robotics production by providing subsidies, lowinterest loans, tax incentives, and land lease benefits to manufacturers of robotic products and enterprises that automate production processes. Thanks to the strategic course aimed at developing the innovation potential and shifting the structural base of the national economy to more knowledge-intensive industries based on innovation, as well as the "Made in China" program, the country is constantly rising in the ranking of innovative economies according to the World Intellectual Property Organization. In 2008, the country was ranked 37th, and ten years later- $17^{\text {th }}[13]$.

In addition, the Chinese government considers international cooperation with Western countries in robotics as one of the most effective means of improving the technological level of products. Now, alliances and partner scientific and technical programs are being created with leading Western manufacturers and innovative foreign startups engaged in promising areas of robotics.

According to the forecast, in 2021, the growth of industrial robotics in China will be only $0,2 \%$ ( $\$ 82,9$ billion), after which it will increase at a slow rate of an average of $6.0 \%$ each year. By the end of 2025, the Chinese robotics market may reach more than $\$ 100$ billion ( $\$ 104,8$ billion), which is 1,45 times more than 2019 . As a result, the Compound annual growth rate (CAGR) for the entire study period from 2014 to 2025 will be $9,3 \%$. Now, this indicator has a value of $13 \%$ (Figure 6).

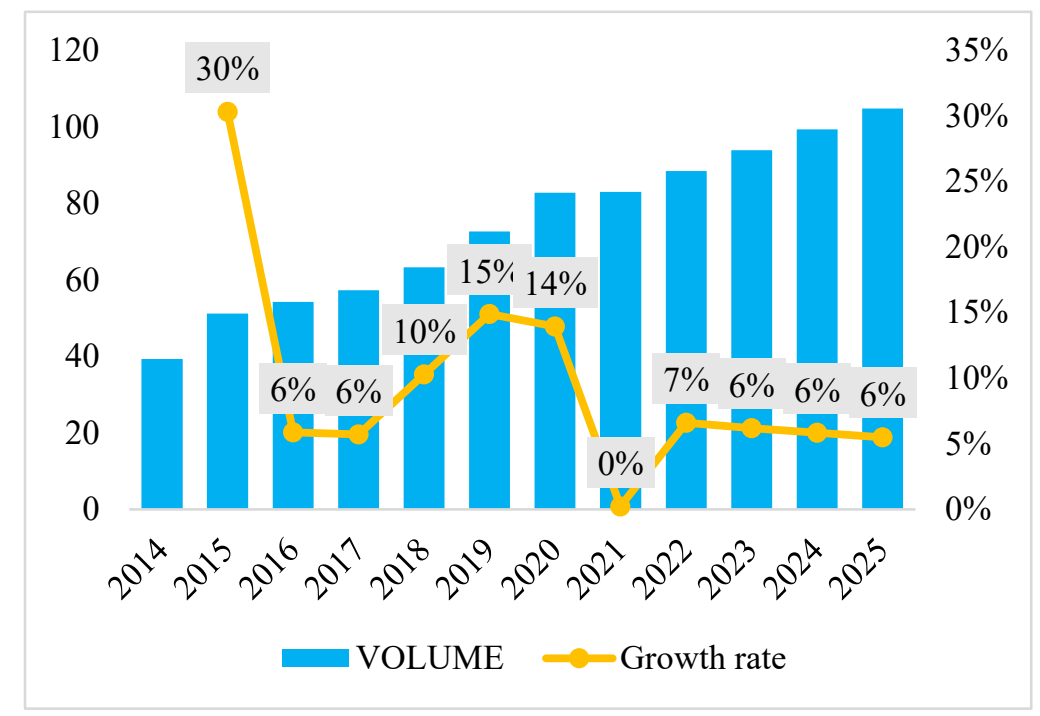

Source: Compiled by the authors, data collected from IFR reports: IFR (2019) [5], IFR (2020) [5].

Fig. 6. The forecast of China robotics market, billion dollars (2014-2025).

The decline in the growth of the Chinese robotics market is due to the consequences of the COVID-19 pandemic and trade tensions between the market leaders: China and the United States. Furthermore, problems in economic relations provoked the redistribution of 
production value chains in 2019, which resulted in a reduction in the global fleet of industrial robots from 422 thousand to 421 thousand units. In addition, most Western countries have introduced strict protectionist measures to protect their strategically essential sectors of the economy, thereby significantly reducing the opportunities for mergers and acquisitions by Chinese companies in industrial innovation.

The Chinese market of industrial robotics can be safely called the largest in the world and, at the same time, rapidly growing. This is what attracts the world's leading manufacturers to open their offices and production sites here. Some foreign companies follow an exciting strategy: they sell their robots to China and then invest in the local industry. Such companies include the German company Kuka AG, the Japanese Yaskawa Electric Corporation, and the Swedish-Swiss multinational corporation ABB Ltd. The government's constant focus on developing the robotics industry encourages Chinese companies to establish close relationships with foreign organizations that possess the most advanced technologies [14].

Despite this, the Chinese market still has problems that hinder faster and better development because the country's potential in this industry is vast. First, it is worth noting the lack of young, highly qualified specialists in China, since today the government has poorly developed educational opportunities for training such personnel [15]. The most popular education system in the specialty "Robotics" is in the United States, and the number of Chinese applicants is growing. Students cannot get the necessary education at home due to the inability of the national education system to respond to market demands in the field of artificial intelligence and robotics flexibly [16].

China is still dependent on imports of industrial robots and their critical components from Japan, Sweden, Germany, Italy, and the United States. Until 2014, European companies imported more than $70 \%$ of industrial robots to China [17].

China is now lagging in key industrial robot control technologies. In particular, the international standards for programmable logic controllers (PLCs) and frequency change controls are not met. It is the poor quality of Chinese robotics, which reduces the service life of robotic systems, holding back the industry's economic growth.

One of the critical problems of the Chinese robotics market can also be called irrational competition among local manufacturers. Many production parks in the country compete to produce similar robots without studying the need and demand well. Since 2014, 40 new industrial parks have been built in the country, specializing in robotics. At the same time, it should be said that Chinese robots are not popular in China. This is quite a controversial fact, but the Chinese, investing in domestic production, still buy imported robots because of the higher quality and much lower cost.

Another critical problem is the dependence of Chinese enterprises on government funding. It is not difficult to notice a reverse side of the coin: many factories cannot afford innovative activities. Soon, about $80-90 \%$ of them may stop working without state subsidies. Now the Chinese government is trying to take measures to combat fraud and corruption, but this will still hinder the development of robotics production in the country in the coming years.

\section{Conclusion}

China is the primary winner in the implementation of the catch-up strategy. In a historically short period, from a backward country in which life expectancy did not exceed 40 years, it grew into the second-largest economy in the world while remaining in the shadow of innovative leaders.

The robotics industry is vital for the future of China's manufacturing industry and many other sectors of the economy [18]. Even though China started large-scale production of industrial robots late, it is now a major global consumer of these products. 
The market of industrial robots in the country is increasing, significantly outpacing the dynamics of global indicators. China is accelerating the production of industrial robots and the introduction of related scientific advances. As a result, the large-scale robotization of the automotive, textile, chemical, logistics, electronics, and household appliances industries carried out by the country's leadership will significantly change national and global production in the future.

Now, this shadow weighs in China. It no longer wants to be a global factory but a "scientific and technological superpower." The worldwide dominance of AI and robotics will ensure this. By consistently implementing the state policy for a new generation of AI since 2017, Beijing has confidently moved into second place in development, behind only the United States.

\section{References}

1. I. Ermolov, Robotics: Industry 4.0 Issues \& New Intelligent Control Paradigms, 272

2. S. O'Meara, Nature, 572 (2019)

3. L. S. Dalenogare, G. B. Benitez, N. F. Ayala, A. G. Frank, Int. J. of Production Economics, 204 (2018)

4. B. Chen, S. Marvin, A. Marvin, Dialogues in Human Geography, 10 (2020)

5. World Robotics 2019 Preview (2019)

6. World Robotics 2020 Report (2020)

7. H. Fan, Y. Hu, L. Tang, J. of Economic Behavior \& Organization (2020)

8. M. S. Reshetnikova, Modern Global Economic System: Evolutional Development vs. Revolutionary Leap, 198 (2021)

9. R. Bogue, IR, 48 (2020)

10. K. Rojko, IIASS, 13 (2020)

11. T. Zhou, E. Lyandres, K. Zhou, X. Cheng, SSRN J. (2020)

12. Worldwide Robotics and Drones Spending Guide (2020)

13. Technology Trends 2019: Artificial Intelligence (2021)

14. P. Aivaliotis, et al., Robotics and Computer-Integrated Manufacturing, 59 (2019)

15. D. Cyranoski. Nature, 553 (2018)

16. J. Stoff, China's Quest for Foreign Technology, 38 (2020)

17. M. Olszewski, PAR, 24 (2020)

18. H. Cheng, R. Jia, R. D. Li, H. Li, J. of Economic Perspectives, 33 (2019) 